\title{
Reliability and validity of trunk accelerometry-derived performance measurements in a standardized heel-rise test in elderly subjects
}

\author{
Stefan Schmid, PT, MA; ${ }^{\text {* }}$ Roger Hilfiker, PT, MPTSc; ${ }^{1-2}$ Lorenz Radlinger, PhD $^{\mathbf{1}}$ \\ ${ }^{1}$ Health, Research and Development Physiotherapy, Bern University of Applied Sciences, Bern, Switzerland; ${ }^{2}$ Health \\ and Social Work, University of Applied Sciences Western Switzerland (HES-SO), Sion, Switzerland
}

\begin{abstract}
This cross-sectional study evaluated the intrasession reliability and concurrent validity of trunk accelerometry (with force plate measurements) for vertical ground reaction force and external mechanical power recorded during a standardized heel-rise (HR) test in 54 elderly subjects (mean +/standard deviation age $81.2+/-6.4 \mathrm{yr}$ ). Peak force as well as peak and average power revealed intraclass correlation coefficients of $>0.75$ and low standard errors of measurement for both the force plate- and the accelerometer-based curves. Correlation coefficients for these variables ranged from 0.95 to 0.98 . The accelerometry-derived variables indicated significantly lower absolute values. Trunk accelerometry can be used as a reliable and valid tool for the quantification of the HR test in the elderly population. However, due to several limitations in the protocol, the use of this tool can currently only be recommended in a test-retest manner. Therefore, more research is needed to fully validate this tool for clinical use.
\end{abstract}

Key words: calf muscle strength, calf raises, concurrent validity, consistency, criterion-related validity, external mechanical power, ground reaction forces, older adults, plantar flexor, reproducibility.

\section{INTRODUCTION}

Considering the six major determinants of gait, originally described by Saunders et al. [1], the heel-rise (HR) movement at the end of stance has been repeatedly shown to have a major impact on the control of the verti- cal displacement of the center of mass (CoM) during normal human gait [2-3]. In addition, Sutherland et al. described the role of the plantar flexors (PFs) in gait as conserving energy by minimizing the vertical CoM oscillation [4].

PF muscle performance has been evaluated with manual muscle testing (testing the ability to move against gravity or against a force applied by the examiner) [5], isokinetic devices for the measurement of isometric peak torque [6], and handheld dynamometers for the measurement of isometric peak force [7]. However, due to the short lever arm (length of the foot), the unilateral standing HR test, commonly quantified by the number of repetitions rather than by the amount of force produced, has been repeatedly recommended over the use of manual resistance [8]. Normative values range from an average of

Abbreviations: $\mathrm{ANOVA}=$ analysis of variance, $\mathrm{BW}=$ body weight, $\mathrm{CoM}=$ center of mass, $\mathrm{CV}=$ coefficient of variation, $\mathrm{HR}=$ heel-rise, $\mathrm{ICC}=$ intraclass correlation coefficient, $\mathrm{MDD}=$ minimum detectable difference, $\mathrm{P}=$ external mechanical power, $\mathrm{PF}=$ plantar flexor, $\mathrm{RFD}=$ rate of force development, $\mathrm{SD}=$ standard deviation, SEM = standard error of measurement, VAcc $=$ vertical acceleration, $\mathrm{VGRF}=$ vertical ground reaction force.

*Address all correspondence to Stefan Schmid, PT, MA; Berner Fachhochschule, Gesundheit, Murtenstrasse 10, 3008 Bern, Switzerland; +41-31-848-37-96; fax: +41-31848-35-01. Email: stefanschmid79@gmail.com

DOI:10.1682/JRRD.2011.01.0003 
2.7 repetitions in older females [9] to 25 in adults aged 20 to 59 years [10] and 36 in children [11]. Intraclass correlation coefficients (ICCs) were found to be high for intrarater reliability (0.89) in adults [9] and excellent for interrater reliability (0.99) in children [11]. Since walking requires the $\mathrm{PF}$ muscles to work in an eccentric-concentric manner, the standing HR test appears to be more appropriate than isometric testing. The major limitation of counting the number of repetitions before exhaustion is that only endurance (the ability to maintain a force or forcegeneration over a certain period of time) is quantified. The counting method lacks the capability to quantify kinetic measures such as force and power.

To measure force and subsequently calculate external mechanical power $(\mathrm{P})$ (power generated on the body's CoM) in a standing HR test, researchers can use force plates. Österberg et al., for example, studied the fatigue process of the calf muscles during an HR test based on torque and work calculations derived from force plate measurements [12]. However, force plates are costly and require sophisticated laboratory installation and therefore are not reasonable for use in everyday clinical practice. Given the limitations associated with simply counting the number of repetitions, as well as the issues with costly force plate equipment, a need for different tools exists.

Recently, the use of trunk accelerometry has been introduced as a cost-effective and easily applied solution for measuring human movement. Several investigations have been conducted using accelerometers for the quantification of gait [13-23], chair rising [24-25], and balance [20,25-27]. High reproducibility has been found using trunk accelerometry for the measurement of spatiotemporal gait parameters [14-15] and accelerations during gait $[15,20]$. In addition, Meichtry et al. reported high validity for quantifying $\mathrm{P}$ using trunk accelerometry and force plate measurements during gait [18].

Elderly people generally display reduced PF strength. This has been shown with manual muscle testing [9], force measurements during isometric PF muscle contractions [28], and ankle power measurements during walking [29]. For this reason, the ability to quantify the kinetic aspects of the HR movement (force, power, etc.) is of particular importance.

The current study evaluated the intrasession reliability and the concurrent (criterion-related) validity of trunk accelerometry with force plate measurements for vertical ground reaction force (VGRF) and P recorded during an HR test in elderly subjects.

\section{METHODS}

\section{Subjects}

Fifty-nine elderly subjects who were living in three different retirement homes were recruited to participate in a larger cross-sectional study that evaluated several activities of daily living as well as other functional tests (i.e., level walking, stair climbing, chair rising, maximal voluntary isometric contraction of the knee extensors, and isolated double-legged HR). The inclusion criteria for the elderly subjects were a minimum age of 65 years and the ability to perform at least one of the following daily-living activities without assistance: standing up from a normal chair, walking 10 meters, and climbing up and down a stair with six steps. Exclusion criteria were acute ailments such as fever or inflammation, as well as any other diagnoses that would prohibit the subject from performing the aforementioned activities. Of the initially recruited 59 subjects, 5 were unable to perform the HR testing procedure, leaving a study population of 54 (Table 1).

The measurements took place at the gymnasium of the Physiotherapy Institute of the Bern University Hospital and in the three local retirement homes.

\section{Instrumentation and Data Acquisition}

A multicomponent force plate (Kistler Type 9286BA; Winterthur, Switzerland) was used to measure VGRF. The signal was amplified with a gain of $2 \times$ by using a universal measurement amplifier (UMVE, uk labs; Kempen, Germany).

For acquisition of the vertical acceleration (VAcc) data, we used a triaxial accelerometer (Model 317A, Noraxon U.S.A. Inc; Scottsdale, Arizona [scaling: $6 \mathrm{~g}$; direct current filter: on]) with three orthogonal axes (anterior-posterior,

Table 1.

Subject demographics.

\begin{tabular}{lc}
\hline \multicolumn{1}{c}{ Parameter } & $\begin{array}{c}\text { n or Mean } \pm \text { Standard } \\
\text { Deviation }\end{array}$ \\
Total Recruited Subjects & 59 \\
Excluded Subjects & 5 \\
Included Male Subjects & 14 \\
Included Female Subjects & 40 \\
Age (yr) & $81.2 \pm 6.4$ \\
Height (m) & $1.62 \pm 0.10$ \\
Weight $(\mathrm{kg})$ & $67.8 \pm 16.9$ \\
Body Mass Index & $25.9 \pm 5.3$ \\
\hline \hline
\end{tabular}


mediolateral, vertical). The accelerometer was attached to the subjects' lower back by an adjustable, nonelastic Velcro fastener belt, with the center of the device on the level of the spinous process of the third lumbar vertebra, which is close to where the CoM is believed to be [27]. The signal was acquired with an 8-channel telemetry system (TeleMyo 2400 G2, Noraxon U.S.A. Inc [resolution: 16 bit; input range $\pm 5 \mathrm{~V}$; noise $<2$ least significant bit; low-pass digital filter: $500 \mathrm{~Hz}$; transmitting rate: $1.5 \mathrm{kHz}$, delay: $100 \mathrm{~ms}$, gain: 1]) that was connected to the previously mentioned universal measurement amplifier. Subjects wore the transmitter unit on their chest.

All data were sampled in sync at a rate of $1 \mathrm{kHz}$ with a 12-bit analog-digital converter (Meilhaus ME-2600i; SisNova Engineering; Zug, Switzerland) and the software package “ads," version 1.12 (uk labs).

\section{Procedures}

After reading the description of the study, signing the consent form, and completing the preparticipation questionnaires, the subjects were equipped with the accelerometer and the transmitter unit. All tests were performed with subjects wearing normal clothes and uniform antislip socks instead of shoes.

The subjects were asked to lift their heels as fast and as high as possible while standing on the force plate with both feet and without bending the knee or hip joints. For balance and safety purposes, the subjects were allowed to touch the examiner's hands during the test with the elbows in $90^{\circ}$ flexion. The test consisted of three single valid HR trials, with rests of 30 seconds in between. A trial was considered valid when the subject was able to clearly lift the heels off the ground without bending knees and hips. Therefore, each trial was visually inspected by a second examiner.

\section{Data Reduction}

Prior to any calculations, we used the mean signal of the unloaded force plate for baseline correction of the VGRF signal. In order to remove possible power-line noise from the VGRF and VAcc data, we used a digital Notch filter with cutoff frequencies of 49 and $51 \mathrm{~Hz}$. Both signals were then low-pass filtered (second-order, zero-lag Butterworth) with a cutoff frequency of $30 \mathrm{~Hz}$.

The starting points of the VGRF and VAcc curves were defined as the points that exceeded two standard deviations (SDs) of the mean of the signals with subjects standing still on the force plate. The end point of the HR movement (i.e., the end of the upswing) was defined as the minimum value following the peak VGRF, respectively the peak VAcc. The VAcc-derived force curves $\left(\mathrm{F}_{\text {VAcc }}\right)$ were calculated according to Newton's second law of motion ( $m$ = body mass in kilograms, $\mathrm{a}_{\mathrm{VAcc}}=$ measured vertical acceleration in meters/seconds squared):

$$
\mathrm{F}_{\mathrm{VAcC}}=m \times \mathrm{a}_{\mathrm{VAcc}} \text {. }
$$

$\mathrm{P}$ was subsequently calculated for the VGRF and VAcc curves based on a previously described algorithm [30]:

$$
\begin{aligned}
\mathrm{P}_{\mathrm{VGRF}} & =\mathrm{F}_{\mathrm{VGRF}} \int_{o}^{t} \frac{\mathrm{F}_{\mathrm{VGRF}}}{m} d t \text { and } \\
\mathrm{P}_{\mathrm{VAcc}} & =\mathrm{F}_{\mathrm{VAcc}} \int_{o}^{t} \mathrm{a}_{\mathrm{VAcc}} d t,
\end{aligned}
$$

where $\mathrm{F}_{\mathrm{VGRF}}$ is the VGRF-derived force curve and $\mathrm{F}_{\mathrm{VAcc}}$ the VAcc-derived force curve. For a sampling frequency of $1 \mathrm{kHz}$, the sampling interval $(d t)$ was $0.001 \mathrm{~s}$. All force and power curves were then normalized to body weight (BW) in newtons and parameterized into the variables peak force $\left(\mathrm{F}_{\max }[\mathrm{BW}]\right)$, time to peak force $\left(\mathrm{tF}_{\max }\right.$ [seconds]), rate of force development (RFD [BW/seconds]), total time (tTotal [seconds]), peak P ( $\mathrm{P}_{\max }$ [watts/BW]), and average $\mathrm{P}\left(\mathrm{P}_{\text {mean }}\right.$ [watts/BW]) (Figure).

All data were analyzed with a custom LabVIEW program (version 8.5, National Instruments, Corp; Austin Texas).

\section{Statistical Analysis}

We performed a repeated-measures analysis of variance (ANOVA) for each of the VGRF- and VAcc-derived variables to rule out a possible systematic error between the three trials (one trial = one HR movement). Intrasession reliability (consistency) was determined with the $\operatorname{ICC}(3,1)$ (i.e., relative reliability) and the standard error of measurement (SEM) (i.e., absolute reliability [response stability]). This three-step reliability approach was suggested by Weir [31]. In addition, we calculated the minimum detectable differences (MDDs) using a 95 percent confidence interval:

$$
\begin{aligned}
& \mathrm{SEM}=\mathrm{SD} \sqrt{1-\mathrm{ICC}} \text { and } \\
& \mathrm{MDD}=\mathrm{SEM} \times 1.96 \sqrt{2} .
\end{aligned}
$$




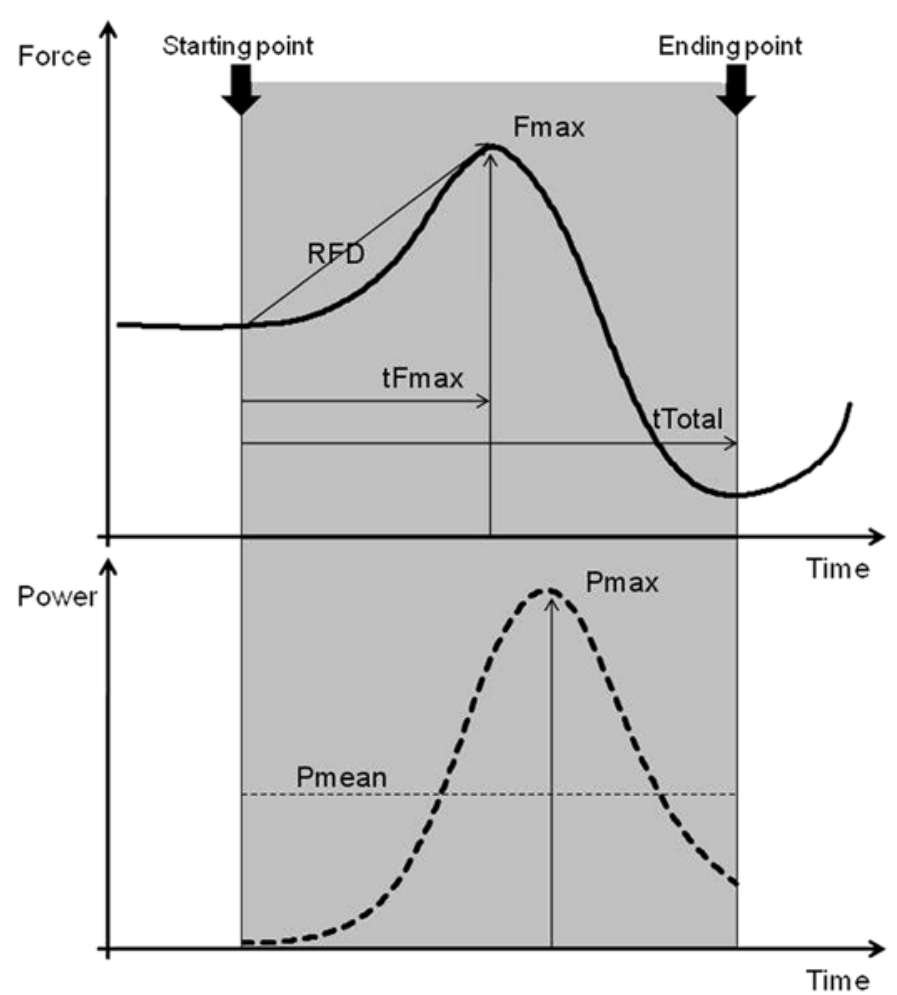

Figure.

Definition of variables: peak force $\left(\mathrm{F}_{\max }\right)$ (body weight), time to peak force $\left(\mathrm{tF}_{\max }\right)$ (seconds), rate of force development (RFD) (body weight/seconds), total time (tTotal) (seconds), peak power $\left(\mathrm{P}_{\max }\right)$ (watts/body weight), and average power $\left(\mathrm{P}_{\text {mean }}\right)$ (watts/body weight) as well as starting and ending points.

Concurrent (criterion-related) validity was analyzed with Pearson correlations for the variables with ICCs $>0.75$. According to Maffiuletti et al., ICCs $>0.75$ could be considered strong [32]. In order to detect statistically significant differences between the VGRF-derived and the VAcc-derived absolute values, we conducted pairedsamples $t$-tests and set significance at the $p<0.05$ level. Finally, the absolute mean differences were expressed as percentages.

Statistical calculations were performed with SPSS 17 for Windows (SPSS, Inc; Chicago, Illinois) as well as Microsoft Excel 2007 (Microsoft, Inc; Redmond, Washington).

\section{RESULTS}

Descriptive statistics and reliability calculations are presented in Table 2. Repeated measures ANOVA revealed no significant systematic error for all variables. ICCs for the VGRF- and VAcc-derived variables ranged from 0.48 to 0.83 and 0.28 to 0.80 , respectively. The highest reliability indexes for the VGRF-derived variables were found for $\mathrm{F}_{\max }$ (ICC $=0.83$; $\mathrm{SEM}=0.059$ ), $\mathrm{P}_{\text {max }}(\mathrm{ICC}=0.83$; $\mathrm{SEM}=0.071)$, and $\mathrm{P}_{\text {mean }}(\mathrm{ICC}=0.81$; $\mathrm{SEM}=0.038)$. RFD revealed an ICC of 0.81 with a rather high SEM (0.836). For the VAcc-derived variables, $\mathrm{F}_{\max }(\mathrm{ICC}=0.79 ; \mathrm{SEM}=0.030), \mathrm{P}_{\max }(\mathrm{ICC}=0.80$; SEM $=0.025)$, and $\mathrm{P}_{\text {mean }}(\mathrm{ICC}=0.78 ; \mathrm{SEM}=0.015)$ indicated the highest reliability. $\mathrm{F}_{\max }, \mathrm{P}_{\max }$, and $\mathrm{P}_{\text {mean }}$ revealed ICCs $>0.75$ for both the VGRF- and VAccderived curves.

Pearson correlation coefficients for these variables $0.98(p<0.001), 0.96(p<0.001)$, and $0.95(p<0.001)$, for $\mathrm{F}_{\text {max }}, \mathrm{P}_{\text {max }}$, and $\mathrm{P}_{\text {mean }}$, respectively, indicated strong concurrent validity. However, the VAcc-derived variables had significantly lower absolute values than the VGRFderived variables, i.e., $-12.76 \pm 4.51$ percent for $\mathrm{F}_{\text {max }}$ $(p<0.05),-72.75 \pm 5.22$ percent for $\mathrm{P}_{\max }(p<0.05)$, and $-71.58 \pm 8.87$ percent for $\mathrm{P}_{\text {mean }}(p<0.05)$. Validity data for these three variables are presented in Table 3.

\section{DISCUSSION}

The quantification of the HR test using trunk accelerometry in the elderly has been shown to be a highly reliable and valid method for the measurement of peak force $\left(\mathrm{F}_{\max }\right)$ and reliable for the measurement of peak and average $\mathrm{P}\left(\mathrm{P}_{\max }\right.$ and $\left.\mathrm{P}_{\text {mean }}\right)$. Based on the high ICCs and the respective low SEM values, $F_{\max }$ was considered to be the most reliable parameter. $\mathrm{P}_{\max }$ and $\mathrm{P}_{\text {mean }}$ also showed high ICCs, but in relation to the absolute value of $\mathrm{F}_{\text {max }}$, had larger SEMs. Another high relative reliability index has been revealed for the force plate-derived RFD variable. However, the corresponding SEM was too large to consider the variable as reliable. In addition, the accelerometry-based RFD showed low relative and considerably large absolute reliability. The reliability of the temporal variables ( $\mathrm{tF}_{\max }$ and tTotal) has been proven to be very weak in terms of both the relative as well as the absolute indexes. Since the calculation of RFD included the temporal variable $\mathrm{tF}_{\max }$, the poor reliability could therefore be explained by the weak reproducibility of the temporal variables.

These results largely support the results of other investigations using trunk accelerometry for the quantification of human movement. Hartmann et al. showed 
Table 2.

Descriptive statistics (mean $\pm \mathrm{SD}$ ), test for systematic error (ANOVA), reliability indexes (ICC and SEM), and MDD for variables $\mathrm{F}_{\text {max }}$ (body weight), $\mathrm{FF}_{\max }$ (seconds), RFD (body weight/seconds), tTotal (seconds), $\mathrm{P}_{\max }$ (watts/body weight), and $\mathrm{P}_{\text {mean }}$ (watts/body weight).

\begin{tabular}{|c|c|c|c|c|c|c|c|c|c|c|}
\hline \multirow{2}{*}{ Variable } & \multicolumn{5}{|c|}{ VGRF-Derived } & \multicolumn{5}{|c|}{ VAcc-Derived } \\
\hline & Mean \pm SD & $p$-Value & ICC & SEM & MDD & Mean \pm SD & $p$-Value & ICC & SEM & MDD \\
\hline$\overline{F_{\text {max }}}$ & $1.28 \pm 0.14$ & 0.07 & $0.83^{*}$ & 0.059 & 0.162 & $1.12 \pm 0.07$ & 0.08 & $0.79^{*}$ & 0.030 & 0.082 \\
\hline $\mathrm{tF}_{\max }$ & $0.18 \pm 1.89$ & 0.81 & 0.50 & 0.046 & 0.127 & $0.11 \pm 0.05$ & 0.13 & 0.31 & 0.038 & 0.105 \\
\hline RFD & $0.39 \pm 0.09$ & 0.22 & 0.81 & 0.836 & 2.317 & $1.28 \pm 1.11$ & 0.23 & 0.62 & 0.687 & 1.904 \\
\hline tTotal & $0.37 \pm 0.17$ & 0.83 & 0.48 & 0.065 & 0.180 & $0.30 \pm 0.07$ & 0.46 & 0.28 & 0.056 & 0.155 \\
\hline $\mathrm{P}_{\max }$ & $0.37 \pm 0.17$ & 0.10 & $0.83^{*}$ & 0.071 & 0.197 & $0.10 \pm 0.06$ & 0.11 & $0.80^{*}$ & 0.025 & 0.069 \\
\hline
\end{tabular}

Note: $p$-values from ANOVA; MDD at 95 percent confidence.

*Indicates ICCs $>0.75$.

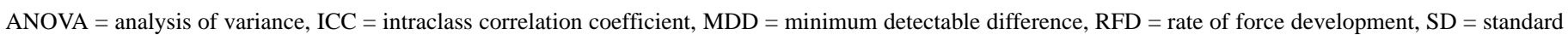
deviation, SEM = standard error of measurement, VAcc = vertical acceleration, VGRF = vertical ground reaction force.

Table 3.

Validity calculations for force $\left(\mathrm{F}_{\max }\right)$ and average and peak power $\left(\mathrm{P}_{\text {mean }}, \mathrm{P}_{\text {max }}\right)$ variables. All variables presented were significant at $p<$ 0.001 .

\begin{tabular}{lcc}
\hline Variable & $\begin{array}{c}\text { Pearson } \\
\text { Correlation }(\boldsymbol{r})\end{array}$ & $\begin{array}{c}\text { Absolute Difference } \\
\text { VGRF to VAcc (\%) } \\
\text { (Mean } \pm \text { SD) }\end{array}$ \\
\hline $\mathrm{F}_{\max }$ & 0.98 & $-12.76 \pm 4.51$ \\
$\mathrm{P}_{\max }$ & 0.96 & $-72.75 \pm 5.22$ \\
$\mathrm{P}_{\text {mean }}$ & 0.95 & $-71.58 \pm 8.87$ \\
SD = standard deviation, VAcc $=$ vertical acceleration, VGRF = vertical \\
ground reaction force.
\end{tabular}

excellent intra- and interrater and test-retest reliability of spatio-temporal gait parameters with ICCs between 0.86 and 0.99 and coefficients of variation (CVs) between 1 and 4 percent [14]. In addition, ICC values between 0.94 and 0.96 and measurement error values of $0.009 \mathrm{~m}$ for step length, $0.022 \mathrm{~m}$ for stride length, and $1.644 \mathrm{step} /$ min for cadence have been found [15]. Also, test-retest reliability for acceleration measures during gait has been proven to be high, with ICCs between 0.79 and 0.93 and CVs between 2.88 percent and 6.8 percent $[15,20]$. Meichtry et al. reported high correlations $(r>0.82)$ for $\mathrm{P}$ values derived from trunk accelerometry and force plate measurements during gait and concluded the accelerometer is a valid measurement tool [18].

Despite the good reliability indexes for $\mathrm{F}_{\max }, \mathrm{P}_{\max }$, and $\mathrm{P}_{\text {mean }}$, the accelerometry-derived variables were significantly underestimated compared with the force plate measurements. While $\mathrm{F}_{\max }$ showed a difference in the absolute values of about 13 percent, the difference for the $\mathrm{P}$ variables was about 72 percent. We believe that these large differences were mainly due to a tilt of the acceler- ometer. An inaccurate positioning over the lumbar spine, the lumbar curvature, or a forward leaning of the trunk might have caused the device to be slightly inclined in the sagittal plane.

Moe-Nilssen presented an algorithm to calculate the average tilt of an accelerometer device during walking by estimating the gravitational components in the anteriorposterior and mediolateral directions [33]. However, in the current study, the gravitational component was disabled by using a direct current filter during the measurements. Therefore, a retrospective inclination correction was not possible. In addition, this algorithm was developed to correct for the inclination during a periodic movement like walking. In the current study, only single movement tasks were performed, and therefore, the algorithm might not have been appropriate. It might be possible that the algorithm would be applicable for the quantification of the classic HR testing routine, i.e., repetitive HRs without resting periods in between.

Likely, the most accurate solution for correcting the tilt angle would have been the use of an inclinometer, i.e., gyroscope. However, this was not the purpose of the current study. Further, most accelerometry systems designed for measuring physical activity in everyday clinical practice do not contain integrated gyroscopes.

The difference between the VGRF-derived and the VAcc-derived $P$ values has been shown to be much bigger than that between the force values. This has been assumed to be mainly due to the double-integration procedure used for the calculation of $\mathrm{P}$.

In contrast to the results of Hartmann et al. and Henriksen et al., the temporal variables in the current study were least reliable [14-15]. A possible explanation for 
this could be use of a belt to attach the accelerometer. In contrast, Hartmann et al. attached the accelerometer using sport tape [14]. Attachment with the belt might have caused a temporal distortion between the acceleration signals measured by the accelerometer and derived from the force plate measurements. On the other hand, Henriksen et al. also used a belt to attach the device and found high reliability for temporal parameters [15].

Other reasons for the low reproducibility of the temporal variables could be the number of test trials. Janssen et al., for example, tested six trials and found the accelerometer to be a valid tool for the measurement of the duration of the sit-to-stand movement [24].

The uncorrected inclination of the device, use of the belt to attach the device to the lower back, as well as the number of test trials were considered limitations of the current study design. Future research should therefore focus on correcting the inclination angle and attaching the device in a way that prevents temporal distortions, e.g., attaching the accelerometer to the skin with sport tape. In addition, more test trials (e.g., up to five) should be performed.

\section{CONCLUSIONS}

Trunk accelerometry has been found to be a reliable and valid tool for the measurement of peak force and a reliable tool for monitoring peak and average $P$ generated during a double-legged HR test in the elderly population. We believe that the significantly lower accelerometryderived absolute values were mainly due to the uncorrected sagittal inclination of the accelerometer. Further limitations include attachment of the device with a belt as well as an insufficient number of test trials. Therefore, the protocol should only be used in a test-retest situation.

\section{ACKNOWLEDGMENTS}

\author{
Author Contributions: \\ Conception and design: R. Hilfiker, L. Radlinger. \\ Obtained funding: R. Hilfiker, L. Radlinger. \\ Data collection: R. Hilfiker, L. Radlinger, S. Schmid. \\ Analysis and interpretation: S. Schmid, L. Radlinger. \\ Drafting of article: S. Schmid. \\ Revision of article: R. Hilfiker, L. Radlinger. \\ Final approval of article: S. Schmid, R. Hilfiker, L. Radlinger. \\ Financial Disclosures: The authors have declared that no competing \\ interests exist.
}

Funding/Support: This material was based on work supported by the Bern University of Applied Sciences, Switzerland (grant

10158VPT_WGS).

Additional Contributions: The authors would like to thank Senevita AG (Wabern, Switzerland) for their cooperation. Senevita AG is the parent organization of the retirement homes at which the study was conducted and was not involved in data collection, analysis, or interpretation or writing or submission of the article.

Institutional Review: The local ethics commission did not require a review of the study protocol, and all subjects gave informed consent. Participant Follow-Up: The authors do not plan to inform participants of the publication of this study. However, participants have been encouraged to check the study Web site for updated publications.

\section{REFERENCES}

1. Saunders JB, Inman VT, Eberhart HD. The major determinants in normal and pathological gait. J Bone Joint Surg Am. 1953;35-A(3):543-58. [PMID: 13069544$]$

2. Della Croce U, Riley PO, Lelas JL, Kerrigan DC. A refined view of the determinants of gait. Gait Posture. 2001;14(2): 79-84. [PMID: 11544057] DOI:10.1016/S0966-6362(01)00128-X

3. Kerrigan DC, Della Croce U, Marciello M, Riley PO. A refined view of the determinants of gait: Significance of heel rise. Arch Phys Med Rehabil. 2000;81(8):1077-80. [PMID: 10943758] DOI:10.1053/apmr.2000.6306

4. Sutherland DH, Cooper L, Daniel D. The role of the ankle plantar flexors in normal walking. J Bone Joint Surg Am. 1980;62(3):354-63. [PMID: 7364808]

5. Hislop H, Montgomery J. Daniels and Worthingham's muscle testing: Techniques of manual examination. 8th ed. Philadelphia (PA): Saunders; 2007.

6. Elder GC, Kirk J, Stewart G, Cook K, Weir D, Marshall A, Leahey L. Contributing factors to muscle weakness in children with cerebral palsy. Dev Med Child Neurol. 2003; 45(8):542-50. [PMID: 12882533] DOI:10.1111/j.1469-8749.2003.tb00954.x

7. Taylor NF, Dodd KJ, Graham HK. Test-retest reliability of hand-held dynamometric strength testing in young people with cerebral palsy. Arch Phys Med Rehabil. 2004;85(1): 77-80. [PMID: 14970972] DOI:10.1016/S0003-9993(03)00379-4

8. Yocum A, McCoy SW, Bjornson KF, Mullens P, Burton GN. Reliability and validity of the standing heel-rise test. Phys Occup Ther Pediatr. 2010;30(3):190-204. [PMID: 20608857] DOI:10.3109/01942631003761380

9. Jan MH, Chai HM, Lin YF, Lin JC, Tsai LY, Ou YC, Lin DH. Effects of age and sex on the results of an ankle plantar-flexor manual muscle test. Phys Ther. 2005;85(10): 1078-84. [PMID: 16180956] 
10. Lunsford BR, Perry J. The standing heel-rise test for ankle plantar flexion: Criterion for normal. Phys Ther. 1995; 75(8):694-98. [PMID: 7644573]

11. Maurer C, Finley A, Martel J, Ulewicz C, Larson CA. Ankle plantarflexor strength and endurance in 7-9 year old children as measured by the standing single leg heel-rise test. Phys Occup Ther Pediatr. 2007;27(3):37-54. [PMID: 17613455]

12. Österberg U, Svantesson U, Takahashi H, Grimby G. Torque, work and EMG development in a heel-rise test. Clin Biomech (Bristol, Avon). 1998;13(4-5):344-50. [PMID: 11415806]

13. Brandes M, Zijlstra W, Heikens S, Van Lummel R, Rosenbaum D. Accelerometry based assessment of gait parameters in children. Gait Posture. 2006;24(4):482-86.

[PMID: 16427287]

DOI:10.1016/j.gaitpost.2005.12.006

14. Hartmann A, Murer K, De Bie RA, De Bruin ED. Reproducibility of spatio-temporal gait parameters under different conditions in older adults using a trunk tri-axial accelerometer system. Gait Posture. 2009;30(3):351-55.

[PMID: 19628391]

DOI:10.1016/j.gaitpost.2009.06.008

15. Henriksen M, Lund H, Moe-Nilssen R, Bliddal H, Danneskiod-Samsøe B. Test-retest reliability of trunk accelerometric gait analysis. Gait Posture. 2004;19(3):288-97.

[PMID: 15125918$]$

DOI:10.1016/S0966-6362(03)00069-9

16. Hodt-Billington C, Helbostad JL, Moe-Nilssen R. Should trunk movement or footfall parameters quantify gait asymmetry in chronic stroke patients? Gait Posture. 2008;27(4): 552-58. [PMID: 17897830]

DOI:10.1016/j.gaitpost.2007.07.015

17. Laessoe U, Hoeck HC, Simonsen O, Voigt M. Residual attentional capacity amongst young and elderly during dual and triple task walking. Hum Mov Sci. 2008;27(3):496512. [PMID: 18226839]

DOI:10.1016/j.humov.2007.12.001

18. Meichtry A, Romkes J, Gobelet C, Brunner R, Müller R. Criterion validity of 3D trunk accelerations to assess external work and power in able-bodied gait. Gait Posture. 2007;25(1):25-32. [PMID: 16483779]

DOI:10.1016/j.gaitpost.2005.12.016

19. Mizuike C, Ohgi S, Morita S. Analysis of stroke patient walking dynamics using a tri-axial accelerometer. Gait Posture. 2009;30(1):60-64. [PMID: 19349181]

DOI:10.1016/j.gaitpost.2009.02.017

20. Moe-Nilssen R. Test-retest reliability of trunk accelerometry during standing and walking. Arch Phys Med Rehabil. 1998;79(11):1377-85. [PMID: 9821897]

DOI:10.1016/S0003-9993(98)90231-3
21. Moe-Nilssen R, Helbostad JL. Estimation of gait cycle characteristics by trunk accelerometry. J Biomech. 2004; 37(1):121-26. [PMID: 14672575] DOI:10.1016/S0021-9290(03)00233-1

22. Terrier P, Dériaz O, Meichtry A, Luthi F. Prescription footwear for severe injuries of foot and ankle: Effect on regularity and symmetry of the gait assessed by trunk accelerometry. Gait Posture. 2009;30(4):492-96.

[PMID: 19709884]

DOI:10.1016/j.gaitpost.2009.07.122

23. Yack HJ, Berger RC. Dynamic stability in the elderly: Identifying a possible measure. J Gerontol. 1993;48(5): 225-30. [PMID: 8366265]

24. Janssen WG, Bussmann JB, Horemans HL, Stam HJ. Validity of accelerometry in assessing the duration of the sit-to-stand movement. Med Biol Eng Comput. 2008;46(9): 879-87. [PMID: 18626677] DOI:10.1007/s11517-008-0366-3

25. Janssen WG, Külcü DG, Horemans HL, Stam HJ, Bussmann JB. Sensitivity of accelerometry to assess balance control during sit-to-stand movement. IEEE Trans Neural Syst Rehabil Eng. 2008;16(5):479-84.

[PMID: 18990651]

DOI:10.1109/TNSRE.2008.2003386

26. Lamoth CJ, Van Lummel RC, Beek PJ. Athletic skill level is reflected in body sway: A test case for accelometry in combination with stochastic dynamics. Gait Posture. 2009;29(4):546-51. [PMID: 19138522]

DOI:10.1016/j.gaitpost.2008.12.006

27. Moe-Nilssen R, Helbostad JL. Trunk accelerometry as a measure of balance control during quiet standing. Gait Posture. 2002;16(1):60-68. [PMID: 12127188$]$ DOI:10.1016/S0966-6362(01)00200-4

28. Kubo K, Ishida Y, Komuro T, Tsunoda N, Kanehisa H, Fukunaga T. Age-related differences in the force generation capabilities and tendon extensibilities of knee extensors and plantar flexors in men. J Gerontol A Biol Sci Med Sci. 2007;62(11):1252-58. [PMID: 18000145]

29. Judge JO, Davis RB 3rd, Ounpuu S. Step length reductions in advanced age: The role of ankle and hip kinetics. J Gerontol A Biol Sci Med Sci. 1996;51(6):M303-12.

[PMID: 8914503]

DOI:10.1093/gerona/51A.6.M303

30. Li L, Olson MW, Winchester JB. A proposed method for determining peak power in the jump squat exercise. J Strength Cond Res. 2008;22(2):326-31. [PMID: 18550944 DOI:10.1519/JSC.0b013e3181635606

31. Weir JP. Quantifying test-retest reliability using the intraclass correlation coefficient and the SEM. J Strength Cond Res. 2005;19(1):231-40. [PMID: 15705040]

32. Maffiuletti NA, Gorelick M, Kramers-de Quervain I, Bizzini M, Munzinger JP, Tomasetti S, Stacoff A. Concurrent validity and intrasession reliability of the IDEEA 
accelerometry system for the quantification of spatiotemporal gait parameters. Gait Posture. 2008;27(1):160-63. [PMID: 17336070]

DOI:10.1016/j.gaitpost.2007.01.003

33. Moe-Nilssen R. A new method for evaluating motor control in gait under real-life environmental conditions. Part 1: The instrument. Clin Biomech (Bristol, Avon). 1998;13(45):320-27. [PMID: 11415803]

DOI:10.1016/S0268-0033(98)00089-8

Submitted for publication January 10, 2011. Accepted in revised form March 8, 2011.
This article and any supplementary material should be cited as follows:

Schmid S, Hilfiker R, Radlinger L. Reliability and validity of trunk accelerometry-derived performance measurements in a standardized heel-rise test in elderly subjects. J Rehabil Res Dev. 2011;48(9):1137-44.

DOI:10.1682/JRRD.2011.01.0003

ResearcherID: Stefan Schmid, PT, MA: E-8534-2010 